\title{
Instituição de ensino superior: análise das capacidades resilientes diante das políticas de ações afirmativas
}

\author{
Rosa Almeida Freitas Albuquerque \\ Professora do Departamento de Administração da Universidade Federal de Mato Grosso \\ (UFMT). Doutora em Administração pela Universidade Nove de Julho (Uninove). \\ E-mail: prof.rosaalbuquerque@gmail.com (Brasil)
}

\section{Cristiane Drebes Pedron}

Professora do Programa de Pós-Graduação em Administração da Universidade Nove de Julho (Uninove). Doutora em Gestão pelo Instituto Superior de Economia e Gestão (ISEG) da Universidade de Lisboa/Portugal. E-mail: cdpedron@gmail.com (Brasil)

\section{Luc Quoniam}

Professor do Programa de Pós-Graduação em Administração da Universidade Nove de Julho (Uninove). Doutor em Ciências da Informação e da Comunicação pela Université Aix Marseille III. E-mail: mail@quoniam.info (Brasil)

\section{Resumo}

Este estudo tem como objetivo analisar as capacidades resilientes de uma Instituição de Ensino Superior [IES] diante da implementação de Políticas de Ações Afirmativas [PAA]. A pesquisa tem natureza qualitativa e exploratória e foi conduzida a partir de um estudo caso em uma EIS pública brasileira. A coleta de dados deu-se por meio de entrevistas, recolha de dados secundários e observação direta. Apesar de os resultados indicarem que as capacidades resilientes de colaboração, adaptação, consciência da situação e identificação das vulnerabilidades possam influenciar positivamente na implementação das PAA em uma IES pública, constatou-se que, na organização estudada, é necessário um maior envolvimento dos diferentes stakeholders para se desenvolver a capacidade de colaboração e identificação das vulnerabilidades diante da adoção das PAA.

Palavras-chave: Políticas de ações afirmativas. Resiliência organizacional. Instituições públicas de ensino superior. 


\title{
Higher education institution: analysis of resilient capacities through affirmative action policies
}

\begin{abstract}
This study aims to analyze the resilience capacities of a higher education institution towards affirmative action policies [AAP] implementation. This research has a qualitative and exploratory nature, and it was conducted in a Brazilian public HEI. We collected data through interviews and direct observation. We also analyzed secondary data. Findings indicate that resilient capacities of collaboration, adaptation, situation conscious, and vulnerability identification may have a positive influence of the AAP in a public HEI. However, we observed a need for more involvement of stakeholders in order to develop capabilities such as collaboration and vulnerability identification.
\end{abstract}

Keywords: Affirmative action policies. Higher education institutions. Organizational resilience. Public administration.

\section{Como referenciar em APA:}

Albuquerque, R. A. F., Pedron, C. D., \& Quoniam, L. (2019). Instituição de ensino superior: análise das capacidades resilientes diante das políticas de ações afirmativas. R.G.Secr.,GESEC, 10(1), 47-72.

\section{Como referenciar em ABNT:}

ALBUQUERQUE, R. A. F.; PEDRON, C. D.; QUONIAM, L. Instituição de ensino superior: análise das capacidades resilientes diante das políticas de ações afirmativas. R.G.Secr.,GESEC, São Paulo, v. 10, n. 1, p. 47-72, jan.-abr. 2019.

\section{THOMSON REUTERS}
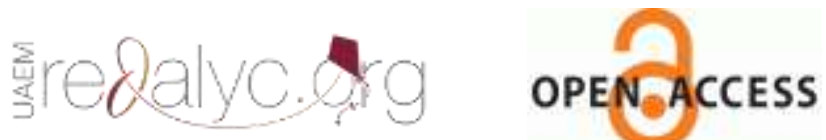


\section{Introdução}

Já não é recente no Brasil a preocupação em garantir um tratamento positivamente diferenciado a determinados grupos de pessoas em função da discriminação de que são vítimas. As reivindicações formais tiveram início em 1930, porém, foi em 2001, na III Conferência Mundial contra o Racismo, Discriminação Racial, Xenofobia e Intolerância Correlata, que o governo brasileiro assumiu mais uma vez o compromisso de implementar políticas públicas de combate às desigualdades que tem repercussões na atualidade (Moehlecke, 2002). Essas políticas, que buscam a concretização de igualdade substancial e material denominam-se de "ação afirmativa" (Gomes \& Silva, 2001). Segundo Gomes e Silva (2001), as ações afirmativas são um conjunto de políticas públicas e privadas concebidas para combater à discriminação racial, de gênero, por deficiência física e de origem nacional que visam mitigar os efeitos de discriminação praticados no passado permitindo a igualdade de acesso a bens como educação e emprego.

Uma das principais iniciativas do país com as políticas de ações afirmativas [PAA] se apresenta nas Instituições de Ensino Superior [IES] por meio de cotas à universidade. As IES têm grande dificuldade de colocar as PAA em prática e obter êxito, já que o debate sobre o assunto é antagônico e complexo. Essas constatações são verificadas em vários estudos, como em Munanga (2001), Segato (2006), Goldemberg e Durham (2007) e Leite (2011).

Alguns autores consideram as PAA como medidas compensatórias, ou seja, um mecanismo alternativo para contrabalancear situações de desigualdade e fragilidade social de determinado grupo reconhecido socialmente por erros e/ou injustiças sociais (Gomes, 2002). Outros autores reconhecerem nas PAA a possibilidade de políticas de inclusão social e a importância de colocarem a questão racial em foco (Da Silva, 2005). Ambos os argumentos trazem uma discussão que não pode ser adiada: o papel da universidade frente aos desafios contemporâneos e a sua efetiva democratização (Passos, 2015).

Essas condições adversas podem ser constatadas quando se observa a trajetória de adoção das PAA pelas Universidades Federais. O lento cenário de adoção de PAA foi alterado com a implementação da Lei $n^{\circ} 12.711$, de 29 de agosto de 2012, a qual torna obrigatória a reserva de vagas para pretos, pardos, indígenas, estudantes de escola pública e de baixa renda nas instituições federais de ensino superior e técnico (Toubia \& Lima, 2015). Nesta lei existe 
uma restrição temporal prevista de 10 anos para que os estudantes pretos, pardos e indígenas, bem como aqueles que tenham cursado integralmente o ensino em escolas públicas tenham acesso as IES. Percebe-se um lento processo de adoção das PAA pelas IES brasileiras, significando um despreparo e/ou falta de interesse político de colocar em prática uma exigência imposta por lei.

Uma lente teórica que pode auxiliar na análise crítica desta situação é a resiliência organizacional. A resiliência organizacional refere-se à capacidade de indivíduos, grupos, organizações e sistemas, de responder de forma proativa à uma mudança significativa que perturba o padrão esperado de eventos, sem se envolver em um longo período de comportamentos retroativos (Horne \& Orr, 1997).

No campo organizacional o conceito de resiliência é recente (Burnard \& Bhamra, 2011; McCann, Selsky \& Lee, 2009; Vickers \& Kouzmin, 2001; Salgado, 2012). O termo começou a ser aplicado no início de 1990, mas ganhou popularidade como uma qualidade que pode contribuir com as organizações e grupos dentro das organizações a se adaptar e prosperar em ambientes difíceis ou voláteis (Cho, Mathiassen \& Robey, 2007; Godwin \& Amah, 2013; Chan, 2011; Boin \& Eeten, 2013; Lana, McCormack \& Richardson, 2013). A resiliência organizacional está sustentada em processos organizacionais que valorizam a competência e o crescimento da organização, especialmente a capacidade para aprender (Sutcliffe \& Vogus, 2003).

Os conceitos de resiliência foram adotados por diferentes teóricos em variadas abordagens no campo científico, como a complexidade e a teoria do caos, da institucionalista racial, das teorias organizacionais de gestão, da macroeconômica, da engenharia e da psicologia, as quais provocaram atenção para a pesquisa de políticas (Capano \& Woo, 2017). Isto porque, segundo os autores, a resiliência permite entender as mudanças políticas e a estabilidade porque se refere à capacidade de políticas persistirem ao longo do tempo superando choques externos e perturbações internas. Além disso, o conceito parece fornecer oportunidades para desenvolver processos políticos para design das políticas, ou seja, para desenvolver processos de políticas para lidar com as mudanças e choques e, portanto, com as incertezas, seja mantendo a estabilidade ou projetando políticas mais efetivas.

Diante deste contexto, a resiliência na área pública emerge como proposta para que os sistemas sejam capazes de transformar-se e crescer diante das crises. Por exemplo, a Espanha aplica o conceito de resiliência para explicar o desenvolvimento econômico local (Barnet, 
2016). Segundo a autora, a "resiliência" surgiu como um dos conceitos recorrentes quando se considerou a saída da crise econômica.

Sendo assim, o objetivo deste estudo é analisar as capacidades resilientes de uma IES diante da implementação de políticas de ações afirmativas. Para tanto, foi realizado um estudo de caso em um IES pública brasileira que implementou PAA. Este estudo considerou o papel da universidade em estudo não apenas em relação a sua responsabilidade diante do grave problema da exclusão educacional, mas também de que forma a mesma está implementando as PAA de modo que garanta ao estudante o acesso, à permanência e o sucesso acadêmico no curso desde o seu ingresso até a sua conclusão.

O artigo está organizado em seis partes. Após esta introdução é apresentado o referencial teórico sobre as políticas de ações afirmativas e resiliência organizacional. Em seguida, inserese a metodologia, o caso de estudo e a discussão. Finalmente, a pesquisa é concluída, destacando-se sugestões de investigações futuras.

\section{Referencial Teórico}

2.1 Políticas de ações afirmativas no ensino superior no brasil

"Políticas públicas são instrumentos de intervenções responsáveis pela organização de uma determinada sociedade, transformando a trajetória e as condições de vida de sua população" (Cruz Neto \& Moreira, 1999, p. 8). Na educação, as políticas foram impulsionadas pelo mercado, que exigia uma força de trabalho mais capacitada e apta a "aprender a aprender" e a atender as qualificações que vão sendo requeridas, aprimorando novas habilidades e competências exigidas na sociedade contemporânea (Aprile \& Barone, 2009).

Diante dessas demandas, o Estado, como o mantenedor em garantir aos indivíduos o acesso à educação, realizou a implementação de políticas públicas como o Programa Universidade para Todos [PROUNI] (Aprile \& Barone, 2009) e o Fundo de Financiamento ao Estudante do Ensino Superior [FIES] (Moura, 2014). Além desses, estão o programa de Apoio a Planos de Reestruturação e Expansão das Universidades Federais [REUNI] (REUNI, 2016) e a Universidade Aberta do Brasil [UAB] (Pereira \& da Silva, 2010). Todos esses programas tinham o propósito de ampliar o acesso ao ensino superior, sendo considerados como PAA. 
As ações afirmativas são medidas de caráter urgente e temporárias, dada à realidade de desigualdade aguda na qual um grupo de pessoas deixa de ter alguns de seus direitos mais elementares observados, de modo a comprometer a dignidade humana (Benedito, 2002). As implementações dessas políticas nas IES não foram facilitadas por uma parte da sociedade ou do estado. Elas levaram um longo tempo até alcançarem sua consolidação. Guimarães (2007) e Feres Júnior, Daflon, Ramos e Miguel (2013) argumentam que as causas disso não estão propriamente nas ações afirmativas, mas sim no mecanismo utilizado pelas instituições para implementá-la, as cotas. Outros ainda argumentam que esta resistência está na desinformação sobre assunto "cotas" (Santos, 2015; Gomes, 2001) e no que ele representa para os grupos vulneráveis, sem as quais não possuiriam a mínima chance de ter acesso as oportunidades na educação e no emprego. O que se deve esclarecer é que ação afirmativa não é sinônimo de política de cotas. Na realidade, as cotas constituem apenas um dos modos de implementação de PAA (Gomes, 2001).

No Brasil, as primeiras iniciativas no contexto das PAA surgiram logo em seguida a Conferência de Durban, em 2001 (Dos Santos, 2012; Haas \& Linhares, 2012). As primeiras universidades brasileiras a realizarem algum tipo de reservas foram as universidades estaduais - Universidade do Estado do Rio de Janeiro [UERJ] e Universidade Estadual do Norte Fluminense Darcy Ribeiro [UENF] (Daflon, Feres Júnior \& Campos, 2013). Essas duas universidades reservaram $40 \%$ das vagas para a "população negra parda", de acordo com os termos da Lei Estadual n 3.708, de 9 de novembro de 2001.

Em 2002, uma medida semelhante foi instituída, no âmbito da Universidade do Estado da Bahia [Uneb], em seguida, em 2003, pela Universidade do Estado de Mato Grosso do Sul [UEMS] que já implementava uma cota para índios; e também pela Fundação Joaquim Nabuco, de Recife - 40\% para afrodescendentes em todos os seus cursos (Medeiros, 2005). A Universidade de Brasília [UnB] foi responsável por dar início a um processo que foi seguido por outras universidades públicas, que culminou com a aprovação da Lei 12.711, de 2012 (Dos Santos, 2012).

Assim, mesmo diante das críticas a tais iniciativas feitas por aqueles que julgam as diferenças sociais e raciais dos negros, comparativamente à dos brancos, como inferioridade, anormalidade, desvio (Silvério, 2003), os objetivos das ações afirmativas continuam firmes em seus propósitos que é eliminar as desigualdades de forma que não se mantenham grupos 
marginalizados na sociedade, ou seja, busca-se uma composição diversificada onde não haja o predomínio de raças, etnias, religiões e gênero (MEC, 2017).

Os esforços fomentados em prol da implementação das PAA podem ser observados em dois momentos distintos: um antes e outro depois da aprovação da Lei n. 12.711. A lei estipulou que até 2016 pelo menos 50\% das vagas das instituições federais de educação superior fossem reservadas para estudantes de escola pública (Heringer, 2014).

O processo político que motivou o desenvolvimento destas políticas não foi um caminho sem conflitos. Ao contrário, trata-se de um caminho cheio de percalços, permeado por disputas entre diferentes atores envolvidos e também por construção de consensos à custa de muita negociação (Heringer, 2014).

As políticas em operação antes da aprovação da lei atendiam uma diversidade de tipos de beneficiários. A Lei n. 12.711, contudo, fixou quatro subcotas: (1) candidatos egressos de escola pública, (2) candidatos de escolas públicas e baixa renda, (3) candidatos pretos, pardos e indígenas de escolas públicas, e (4) candidatos pretos, pardos e indígenas de escolas públicas e de baixa renda (Feres Júnior et al., 2013).

Os principais beneficiários, segundo levantamento do GEMAA (2013), dessas políticas até 2012 foram os estudantes egressos de escolas públicas, já que as universidades ofereciam resistência a nomear cotas específicas para grupos étnico-raciais. Essa hegemonia foi alterada, pois o efeito da nova lei foi estender, já no primeiro ano de sua operacionalização, as ações afirmativas no que se refere a inclusão étnico-racial. Ou seja, a lei teve o efeito de quebrar essa resistência.

Além disso, a Lei Federal n. 12.711 provocou o fomento da quantidade de universidades federais que adotavam programas de ação afirmativa. Antes da lei, 31\% das IES (18 de 58) não adotavam qualquer política dessa natureza. A lei tornou obrigatória a adoção dessas políticas por todas as universidades. Desta forma, no vestibular de 2013, as universidades que ainda resistiam às ações afirmativas tiveram que adotá-las em cumprimento à nova lei (Feres Júnior et al., 2013).

Diante desses fatos, a lei federal vence de um lado uma resistência histórica das universidades a nomear cotas específicas para pretos, pardos e indígenas e, por outro lado, a suposição de que as cotas sociais seriam suficientes para a inclusão desses grupos, uma vez que eles pertencem às classes sociais mais pobres (GEMAA, 2013). Hoje há nas universidades 
federais uma adesão integral das ações afirmativas, sendo reguladas sobre a égide da Lei $\mathrm{n}$. $12.711 / 2012$.

Entende-se que a resistência às ações afirmativas, foi em parte vencida nas IES federais por força da lei (Feres Júnior \& Daflon, 2014). Contudo, fica explícito que a presença dos sujeitos provenientes das ações afirmativas provoca desconfortos de ordens diversas: a desconstrução do mito da ideologia da "democracia racial", até o desconforto que a explicitação da desigualdade desses sujeitos no contexto universitário tem ocasionado. Quiçá esses problemas perdurem ainda na ambiência universitária na compreensão de Souza e Pereira (2016, p. 7) porque “[...] é preciso enfrentar o novo com o novo”. Estas PAA “[...] chegam para que as universidades repensem a sua estrutura, a sua gestão e o seu conteúdo" (Souza \& Pereira, 2016, p. 7).

\subsection{Resiliência Organizacional}

A resiliência teve sua origem na área de conhecimentos exatos, na física, como a capacidade de um material voltar a seu estado normal depois de ter sofrido tensão (Yunes, Szymanski, \& Tavares, 2001). Nas ciências do comportamento, a resiliência foi inicialmente aplicada para explicar porque as crianças e os jovens, diante de um estresse, são capazes de transpassar as adversidades e se transformarem em indivíduos saudáveis (Zolkoski \& Bullock, 2012).

No campo organizacional, o termo resiliência começou a ser aplicado como uma qualidade organizacional no início de 1990, mas recentemente ganhou popularidade como uma qualidade que pode ajudar as organizações e os grupos dentro das organizações a sobreviver e prosperar em ambientes difíceis ou voláteis (Boin \& Eeten, 2013).

A resiliência organizacional tem sido utilizada para analisar diferentes tipos de fenômenos organizacionais, como os estudos de Horne e Orr (1997), Hamel e Valikangas (2003) e Gittel, Cameron, Lim e Rivas (2006). Esses estudos significam esforços da apropriação do conceito de resiliência organizacional traduzido como lente para o entendimento das diferentes situações enfrentadas pelas organizações.

Horne e Orr (1997) tinham o objetivo de revelar os comportamentos que criavam organizações resilientes. Hamel e Valikangas (2003) também se dedicaram a este assunto, investigando porque algumas organizações obtinham sucesso enquanto outras sucumbiam às 
condições adversas. Gittell et al. (2006) desenvolveram um estudo nas companhias áreas nos Estados Unidos para analisar a relação da lealdade dos empregados e a disponibilidade financeira para o desenvolvimento da resiliência organizacional após os desastres de 11 de setembro.

Apesar dos avanços, a resiliência organizacional ainda é um conceito de pouco consenso (Quedraogo \& Boyer, 2012; Sheffi, 2007), contudo esforços têm sido feitos para melhorar o entendimento do seu significado. Starr, Newfrock e Delurey (2003), por exemplo, apresentam a resiliência como um resultado da capacidade e habilidade da organização para suportar e se adaptar a novos ambientes adversos. Sutcliffe e Vogus (2003) colocam a resiliência como uma ação contínua, ou seja, apesar das adversidades, a organização possui a capacidade para continuar a utilizar seus recursos, tantos internos quando externos, para resolver os problemas decorrentes da estabilidade ambiental. Sheffi (2007) apresenta a resiliência como um fator inerente a organização, ou seja, como a capacidade de a organização ultrapassar por tempos difíceis e em seguida retornar as atividades normais de operacionalização. McCann, Selsky e Lee (2009) revelam a resiliência como uma característica intrínseca a organização, ou seja, como a capacidade da organização para assimilar, se reinventar para responder as mudanças contínuas que não podem ser evitadas.

Assim como o conceito, o que pode ser a resiliência e como a organização pode alcançála tem sido uma preocupação constante. Gibson e Tarrant (2010), por exemplo, revelam que a resiliência surge do resultado da interação de elementos organizacionais, aqui compreendidos com estruturas, sistemas, processos e pessoas que contribuem com a concepção da resiliência quando as organizações se adaptam as mudanças ambientais. Whitehorn (2010) esclarece que a resiliência emerge de uma harmonização dos elementos organizacionais da "cultura e atitude" e "processo e estrutura". Segundo esse autor, a capacidade de resiliência se desenvolve quando todos esses elementos enfrentam condições adversas de forma eficaz.

O problema, no entanto, pode estar na identificação desses fatores pela organização já que Horne e Orr (1997) destacam que o desafio para as organizações é reconhecer que muitos fatores da resiliência estão incorporados nos seus recursos humanos, na estrutura, nas rotinas e nos seus processos organizacionais. Talvez esta questão seja respondida pela reflexão de Sutcliffe e Vogus (2003). Esses autores inferem que a resiliência organizacional não surge 
somente em tempos complexos, ou em resposta a eventos específicos, mas se desenvolve ao longo do tempo no qual a organização vivencia momentos de riscos, tensões e transformações.

Do mesmo modo, Erol, Sauser e Mansouri (2010) percebendo que as organizações agem em ambientes altamente voláteis, mas com grandes oportunidades, propõem dois elementos principais os quais as mesmas precisam observar para criar resiliência. De um lado, têm-se as influências externas que se apresentam na forma de eventos desestabilizastes (mudança culturais e socioambientais), nos requisitos emergentes de negócios (políticos e econômicos) e as mudanças de ambiente de negócios (tecnológico, humano e legal). Do outro lado têm-se as capacidades ou características internas da organização, as quais precisam demonstrar capacidade de adaptabilidade, agilidade, flexibilidade e de conectividade entre os elementos organizacionais para responder eficazmente as variáveis provenientes das influências externas.

Na compreensão de Lengnick-Hall, Beck e Lengnick-Hall (2011), a adaptabilidade, agilidade e flexibilidade são elementos importantes e podem contribuir com a capacidade de resiliência, mas não são suficientes por si só para alcançá-la. Isto porque, segundo esses autores, a necessidade de resiliência é desencadeada por um acontecimento inesperado e a resposta da organização a este acontecimento vem por intermédio da capacidade de renovação, transformação e criatividade de dentro para fora.

Ao longo da revisão da literatura foram identificadas diferentes características da resiliência: (1) flexibilidade; (2) agilidade; (3) adaptabilidade; (4) vulnerabilidade; (5) redundância; (6) robustez; (7) desenvoltura; e (8) tolerância e (9) colaboração. Além dessas McManus (2008) acrescentam a "conscientização da situação" como o motor que impulsiona a tomada de decisão e o desempenho dos sistemas complexos e dinâmicos. A conscientização da situação inclui a melhor compreensão dos fatores impulsionadores das crises, a maior conscientização dos recursos disponíveis, tanto interna como externamente, e a melhor compreensão dos requisitos mínimos do funcionamento organizacional (McManus, 2008).

Apesar de se entender que de forma geral as organizações tenham sido projetadas para operar de forma eficiente e efetiva em ambientes caracterizados pela estabilidade e previsibilidade, sabe-se que devido às condições altamente dinâmicas e as incertezas que parecem se tornar a cada dia mais comuns, as vulnerabilidades das organizações têm se acentuado. Ao longo dos últimos tempos, a volatilidade dos sistemas naturais, econômicos, políticos, culturais e sociais parece aumentar em taxas mais rápidas do que muitas organizações podem lidar. Embora tais condições de rápida movimentação oprimam algumas organizações, 
uma proporção ainda é capaz de demonstrar capacidade de recuperação e gerenciamento dos efeitos adversos da dinâmica e da volatilidade desses sistemas.

Em face a estas questões, Gibson e Tarrant (2010) propuseram o modelo dos "Estágios da Resiliência Organizacional" (Figura 1), o qual retrata uma visão sobre a natureza multidimensional da complexidade da resiliência organizacional e os aspectos diferentes e inter-relacionados desse constructo. Além disso, considerando a resiliência em sua complexidade, entende-se que não se possa utilizar abordagens simplistas e mecanicistas promovidas em torno dessa temática.

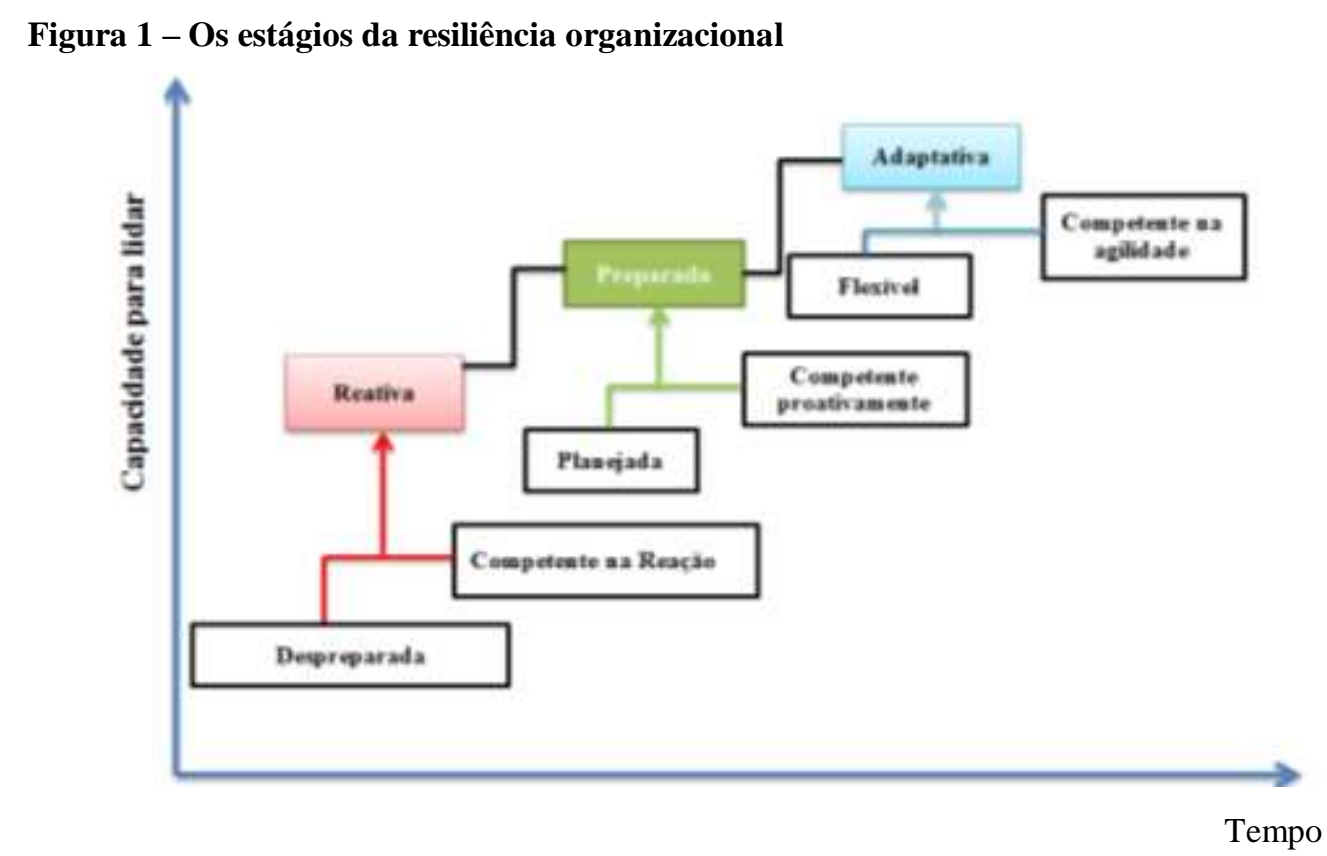

Fonte: Gibson e Tarrant (2010, p. 7).

O modelo é composto por 3 etapas: reativa, preparada e adaptativa. Segundo o modelo, a resiliência pode existir em uma série de condições, tais como de baixa resiliência, nomeada de vulnerabilidade, ou elevada resiliência, denominada de resiliente. Nesse sentido, a resiliência pode ser observada entre diferentes organizações que enfrentam o mesmo evento, ou dentro de uma única organização ao experimentar diferentes tipos de eventos, ou ao longo de diferentes períodos de tempo, ou ainda, internamente entre as diferentes funções dentro de uma organização. Porém, o que Gibson e Tarrant (2010) aduzem, é que à medida que a organização concentra e investe esforços na sua capacidade de resiliência, observa que há uma crescente 
capacidade de resiliência. A partir de um baixo estado reativo como, por exemplo, uma resposta imediata, mas sem grandes impactos, para em seguida melhorar as capacidades resilientes, por intermédio do planejamento tornando-se proativamente competente na resposta preparada e, eventualmente, alcançar um estado, no qual a organização está adaptavelmente preparada face às elevadas condições de incerteza.

\section{Metodologia}

Este estudo que tem como objetivo analisar as capacidades resilientes de uma Instituição de Ensino Superior [IES] diante da implementação de PAA, sendo que possui natureza qualitativa e exploratória. Segundo Godoy (1995, p. 7), estudos nesta perspectiva têm como "prioridade o estudo e a análise do mundo empírico em seu ambiente natural". A escolha pela abordagem qualitativa se justifica uma vez que se pretendeu compreender a natureza de um fenômeno social (Richardson \& Peres, 1989), o qual é abarcado pelas PAA em uma IES pública.

O método adotado foi o estudo de caso, realizado em uma única instituição. Segundo Yin (2010, p. 39), “o estudo de caso é uma investigação empírica que investiga um fenômeno contemporâneo em profundidade e em seu contexto de vida real, especialmente quando os limites entre o fenômeno e o contexto não são claramente evidentes".

O estudo de caso foi realizado na Universidade Federal do Mato Grosso [UFMT], uma IES que está localizada em Cuiabá, no Estado de Mato Grosso. Quanto à abrangência da coleta de dados, foi no campus de Cuiabá-MT, abarcando 5 cursos dos 18 oferecidos pela unidade. Os 5 cursos selecionados foram direito, medicina, serviço social, administração e psicologia. Os critérios para escolha dos cursos, foi o tempo de implementação das PAA.

A coleta de dados foi realizada considerando múltiplas fontes: a entrevista, a análise de dados secundários e a observação direta. A entrevista permitiu o acesso aos dados de difícil obtenção por meio da observação direta, tais como sentimentos, pensamentos e intenções - no caso das pessoas que são vinculadas com as PAA, estudantes da concorrência, estudantes da escola pública, estudantes negros da escola pública, membros do conselho das ações afirmativas, coordenadores dos cursos, professores e técnicos administrativos.

Participaram da pesquisa 43 entrevistados. As entrevistas com os estudantes (11) e os membros do conselho das PAA (8) tiveram duração em torno de 20 minutos, enquanto com os coordenadores (11) em torno de 2 horas a 3 horas e 30 minutos. As entrevistas com os 
professores (11) perduraram em torno de 1 hora e com os técnicos (2) as entrevistas perduraram em torno de 20 minutos. O roteiro semi-estruturado considerou a revisão de literatura e procurou adaptar as questões do estudo de McManus (2008) sobre resiliência organizacional. O número de entrevistados baseou-se no critério da saturação.

A análise de documentos secundários contou com documentos provenientes do Conselho Superior de Ensino [CONSEPE], da Pró-reitoria de Assistência Estudantil [PRAE], relatórios da comissão própria de avaliação da UFMT, folders dos cursos de capacitações dos docentes, projetos pedagógicos dos cursos, documentos do Conselho das PAA entre outros.

As entrevistas foram gravadas, notas de campo foram realizadas ao longo da observação e documentos foram sistematicamente organizados. As entrevistas foram transcritas e tratadas com o auxílio de um software de análise qualitativa de dados [NVivo]. A técnica utilizada para a análise dos dados foi a análise de conteúdo, assim como recomenda Bardin (2011). Pela observação direta foi possível confrontar as informações apresentadas pelos entrevistados.

\section{Estudo de Caso UFMT}

\subsection{Contextualização do Caso}

A UFMT foi criada em 1970 - está localizada no Estado de Mato Grosso - e é composta por cinco campus: Cuiabá, Rondonópolis, Sinop, Araguaia e Várzea Grande. Em 2014, ela oferecia 106 cursos de graduação e estava com 20.308 alunos matriculados. Além disso, 14 cursos de doutorado, 39 mestrados e 19 polos de educação à distância (Relatório de Avaliação Institucional, 2014).

A UFMT iniciou o processo de implementação das PAA em 2003 por intermédio da Resolução CONSEPE n 110 , de 10 de novembro de 2003, quando aprova no mérito, o sistema de sobrevagas que será correspondente a até $30 \%$ das vagas ofertadas em cada curso regular da UFMT. Esta resolução não entrou em vigor na data de publicação, como também não foi constituída a comissão que teria como finalidade de desenvolver estudos, consultar as unidades envolvidas e formular proposta para a implantação das sobrevagas, que seria apreciada num prazo de 90 dias, como planejado pelo Conselho de Ensino, Pesquisa e Extensão. 
Em 2007 foi criado o Programa de Inclusão de Estudantes Indígenas no âmbito da UFMT - Resolução CONSEPE nº 82, de 2007-, por um período de cinco anos a partir de 2008. Apesar de todos os obstáculos que tiveram que ser vencidos, essencialmente pelo convencimento da necessidade de criação das sobrevagas junto aos coordenadores dos cursos de interesse, o programa foi implementado em 2008 e está em operacionalização.

Em 2011 foi criado um Programa de Ação Afirmativa destinado a estudantes egressos de escola pública e estudantes negros pela Resolução CONSEPE nº 97, de 2011. A criação deste programa foi justificada pela constituição da República Federativa do Brasil que estabelece promover o bem de todos, sem preconceitos de origem, raça, sexo, idade, entre outras formas de discriminação; a Lei $n^{\circ}$ 12.288/2010, que instituiu o Estatuto da Igualdade Racial; a Lei n ${ }^{\circ}$ 9394, de 1996, que estabelece as diretrizes e base da educação nacional; a Conferência Nacional de Educação [CONAE-2010]; ainda que para o CONAE, as instituições educativas e os sistemas de ensino devem colaborar na democratização do acesse ao ensino superior; a Resolução CONSEPE nº 82, de 2007, que criou o Programa de Inclusão Indígena e o documento síntese do I Fórum da Diversidade na UFMT, e o documento resultante da pesquisa dos estudantes feito pela Associação Nacional dos Dirigentes das Instituições Federais de Ensino Superior [ANDIFES]. Segundo as diretrizes, o Programa de Ação Afirmativa deveria ser implantado em um período de dez anos a partir de 2012.

Porém, a história de implementação das PAA na UFMT não ocorreu de forma linear, tranquila como apresentado, pelo contrário, o que foi revelado por gestores, professores, coordenadores, técnicos e estudantes entrevistados. Segundo eles, o que foi vivenciado na universidade neste período foram momentos de muitas lutas, debates, confrontos, discussões infindáveis realizadas pelos sindicatos dos técnicos, docentes e a comunidade acadêmica como um todo.

A PRAE, que acompanhou as discussões das políticas desde a sua idealização, revela que a ação afirmativa foi discutida e aprovada em 2003, através da Resolução CONSEPE n. 110, de 10 de dezembro de 2003, motivada por um documento com 6.200 assinaturas que o movimento negro do campus de Rondonópolis encaminhou para a universidade. Esta discussão, lembra a Pró-Reitora entrevistada, era também nacional. Porém, diz ela, "eu faço uma crítica porque aprovou o programa de ação afirmativa na UFMT no mérito". Ou seja, o CONSEPE aprovou o programa, mas delegou a responsabilidade às unidades acadêmicas, para definirem as vagas, os cursos e o período de ingresso dos estudantes, de baixa renda, estudantes negros e 
indígenas. No entanto, segundo declaração da presidente do conselho das PAA, a "UFMT aprova as PAA, mas não executa".

Coincidentemente, a Pró-reitoria apontou que entre o período de 2003 a 2008, período anterior de Reestruturação e Expansão das Universidades Públicas [REUNI], as universidades federais estavam transitando por um período muito difícil, porque não obtinham nenhum respaldo do governo federal para apoiar financeiramente políticas de ampliação de vagas, de laboratório e de recursos de professores. Enfim, estes fatores tornaram um pouco mais difíceis as unidades aceitarem naquele momento ampliar vagas para os estudantes. Mas, como se pode perceber ao longo do relato da Pró-Reitora, a negação e a resistência para executar as PAA pelas unidades acadêmicas permaneceram até 2011, quando por força da lei, a universidade se organizou para implementar uma política que tinha sido aprovada há mais de 9 anos.

Isto começou a mudar a partir do programa indígena, quando a UFMT começou a ter visibilidade no estado e nos municípios, o qual coadunou com as discussões em nível nacional sobre os outros movimentos que instigou os movimentos negros no período de 2009 e 2010 cobrar da universidade a execução da ação afirmativa aprovada em 2003 ou a aprovação de uma nova ação para garantir o ingresso dos estudantes. Diante dessas condições, a universidade retomou as discussões. Enquanto isto, o movimento negro promoveu uma ação no Ministério Público Federal cobrando da UFMT a execução das PAA, que tinham sido aprovadas em 2003. Assim, em 2011, a universidade encaminhou uma proposta no formato das reservas, com reserva de $50 \%$ das vagas para estudantes de escolas públicas, fazendo recorte étnico racial. O tema foi discutido em todas as instâncias da universidade, visto que não é um assunto considerado de consenso, não é unanimidade, pelo contrário, o tema é complexo, a comunidade acadêmica - estudantes, técnicos, professores - ainda têm muitas resistências. Sobre essas forças contrárias, a presidente do conselho relembra que "a implementação da política de ação afirmativa na UFMT foi possível, mas com uma correlação de força muito grande. Uma disputa muito grande".

Mas o CONSEPE, que representa todas as unidades, delibera pela maioria, sendo as PAA aprovadas em 2011, como um programa de ação afirmativa por 10 anos a partir de 2012. O Programa de Ação Afirmativa reservará 50\% das vagas ofertadas, por turno, em todos os cursos de graduação da UFMT, sendo: $30 \%$ para estudantes egressos de escolas públicas e 20\% para estudantes negros egressos de escolas públicas (Resolução CONSEPE, n. 97, 2011). 
4.3 Uma análise das capacidades de resiliência organizacional da UFMT diante da implementação das políticas de ações afirmativas

Esta análise considera o modelo proposto por Gibson e Tarrant (2010) como ponto de partida. Estes autores propõem um modelo que considera como partes integrantes da capacidade de resiliência organizacional a capacidade de consciência da situação, a capacidade de adaptação, a capacidade de colaboração e a capacidade de identificar as vulnerabilidades.

A "consciência da situação" amplia a capacidade da organização sobre todo o seu ambiente, fornecendo a capacidade de reconhecer e agir de acordo com os riscos e oportunidade das diferentes condições, aqui retratadas pela implementação das PAA (Seville, 2008). A "capacidade de adaptação" representa a cultura da organização, sendo que considera os aspectos de uma organização como as estruturas de liderança e tomada de decisão, o conhecimento e o fluxo de informação, o grau de criatividade e flexibilidade que a organização promove ou tolera (Gibson \& Tarrant, 2010). A “capacidade de colaboração" é considerada um dos elementos mais importantes da resiliência organizacional (Pellissier, 2010), pois refere-se à capacidade de as pessoas colaborarem umas com as outras em prol de um objetivo comum. A "capacidade de identificar as vulnerabilidades" refere-se à identificação de fatores que têm influência para desestabilizar o sistema organizacional (McManus, 2008). Esta capacidade está relacionada aos aspectos gerenciais e operacionais de uma organização, que tem o potencial de gerar significativamente os impactos negativos em uma situação de crise (McManus, 2008). Portanto, pelas características apresentadas pela implementação das PAA e por se tratar de uma universidade pública, se entende que as análises dessas capacidades permitirão respostas adequadas aos propósitos da pesquisa.

Fazendo uma leitura do caso da IES estudada a luz do modelo proposto por Gibson e Tarrant (2010), propõem-se a Figura 2: 
Figura 2 - A progressão do estágio da resiliência organizacional

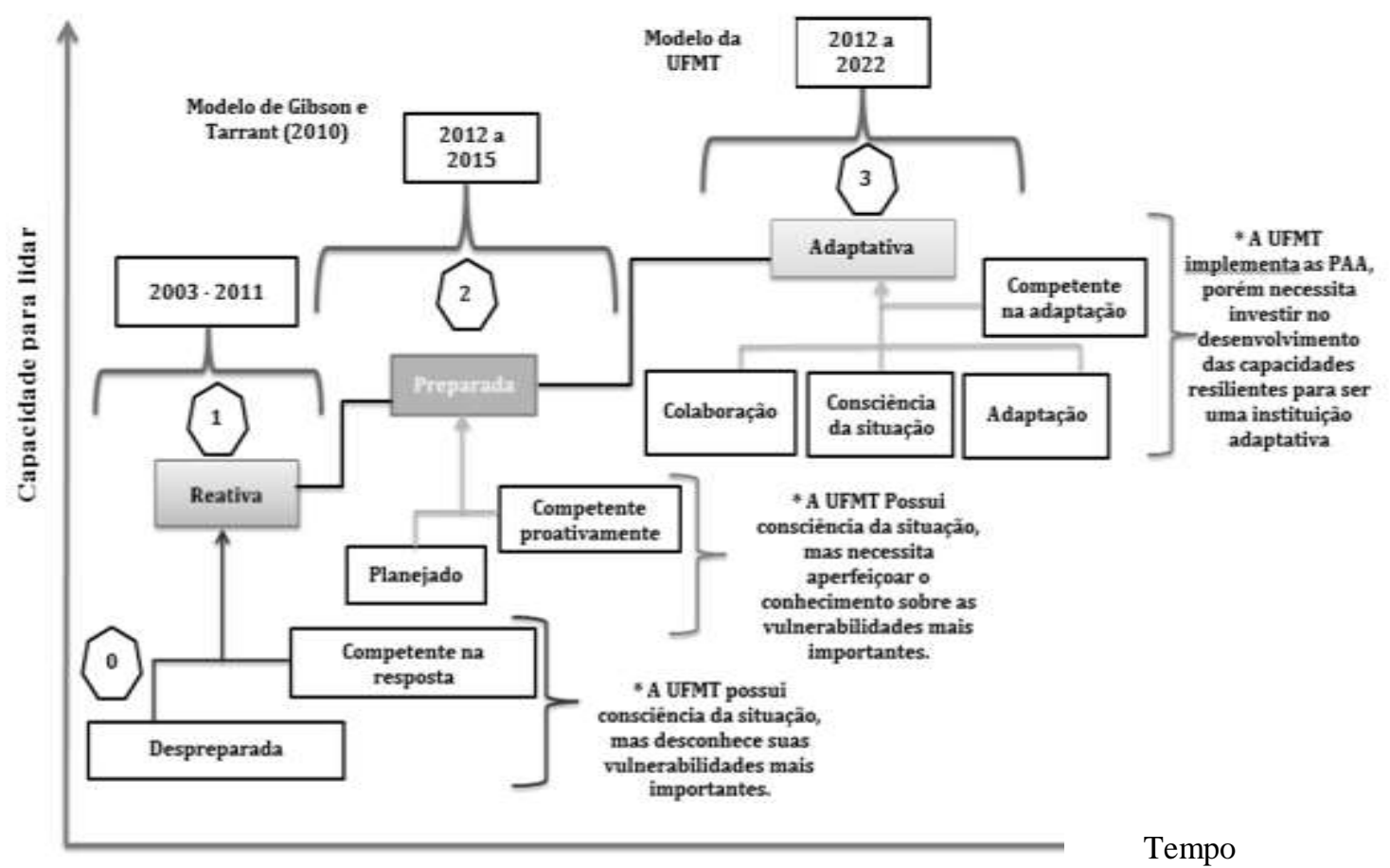

Fonte: Adaptado de Gibson e Tarrant (2010).

Segundo o modelo proposto por Gibson e Tarrant (2010), a resiliência pode existir em uma série de condições, tais como de baixa resiliência, caracterizada de vulnerabilidade ou elevada resiliência, denominada de resiliente. No primeiro caso, a baixa resiliência condiz com as condições apresentadas pela UFMT. Pois se considera, que a universidade em 2003 a 2011 possuía "consciência da situação", mas desconhecia suas vulnerabilidades mais importantes. Isto porque os membros do CONSEPE aprovaram no mérito as políticas de sobrevagas para redução da exclusão acadêmica, quanto ao acesso e a permanência na universidade, de estudantes negros pobres, brancos pobres e indígenas e recomendaram a constituição de uma comissão com a finalidade de desenvolver estudos, consultar as unidades envolvidas e formular proposta para implantação do sistema de sobrevagas, que deveria ter sido apreciada num prazo de 90 dias. A proposta não deixa dúvidas, os membros do CONSEPE queriam utilizar estrategicamente a comissão constituída por representantes pela comunidade acadêmica para mediar a implantação das políticas nas unidades. No entanto, parece que a estratégia que não surtiu o efeito esperado, já que a comissão não foi constituída e as unidades não foram preparadas para a implantação das políticas de sobrevagas como recomendada pelo CONSEPE. 
Porém, segundo as entrevistas dos coordenadores, o mesmo não ocorre com as demandas dos povos indígenas [PROIND]. Em 2006, a universidade recebe a solicitação das vagas pelos representantes indígenas e em 2007 o programa foi implementado. Os coordenadores do programa e dos cursos relatam que foi uma oferta muito difícil já que a resistência aflorou por todo o campus da universidade. A questão primordial revelada pelas entrevistas é que os professores consideravam estes estudantes incapazes de cursar a universidade. Contudo essas questões não impediram a consolidação do PROIND, que desde sua implantação recebeu apoio da Fundação Nacional de Saúde [FUNASA], da Fundação Nacional do Índio [FUNAI], do MEC e depois do Sistema de Educação [SECAD].

O programa PROIND fortalece, segundo a Pró-Reitora, e ganha visibilidade no estado e no município, encontrando-se com outros movimentos que já se articulavam na sociedade. Essas condições impulsionaram, entre 2009 e 2010, os movimentos negros reagirem a esta situação cobrando da universidade a implementação imediata da Resolução 110 ou a aprovação de nova ação afirmativa para o ingresso de alunos na IES. Enquanto aguardava a resposta da universidade, o movimento que previa uma resposta desfavorável se antecipou e entrou com uma ação no Ministério Público Federal, requerendo tal aprovação. Imediatamente, o Ministério Público Federal recomendou que a universidade cumprisse com o determinado na Resolução n. 110. Diante dos fatos, entende-se que o CONSEPE não tinha muitas alternativas e como representante das unidades acadêmicas, aprova as PAA em 2011, por um período de 10 anos com execução a partir de 2012 por todos os cursos da universidade.

No segundo estágio da resiliência, que engloba o período de 2012 a 2015, denominada de "preparada", Gibson e Tarrant (2010) inferem que as capacidades resilientes da instituição melhoram, porque a instituição teve tempo para elaborar o planejamento das ações presentes e futuras tornando-se proativamente competente na resposta preparada. Quando este estágio é analisado pela perspectiva da implementação das PAA na universidade, o que se constata pelas entrevistas e observações no campus são os investimentos realizados na estrutura da universidade para facilitar a implantação das PAA. Nesse mesmo período, foi criada a PRAE que, em 2014, instalou o Conselho das Políticas de Ações Afirmativas, órgão colegiado de caráter consultivo, propositivo e avaliativo, que trabalha com as políticas de ações afirmativas dentro da universidade, ampliando os processos de controle social.

Em termos operacionais algumas ações foram realizadas, como a introdução do tema ações afirmativas no curso de capacitação dos professores em estágio probatório. Além disso, 
foi lançado o edital que contempla projetos que atendam os estudantes oriundos das PAA. Somam-se a isso, os investimentos para melhorar acessibilidade das pessoas com deficiências, como piso tátil em algumas unidades, rampas nos pontos de ônibus, instalação de elevadores, investimentos na iluminação, limpeza entre outros.

O terceiro e último estágio da resiliência organizacional apresentado por Gibson e Tarrant (2010), contém os atributos que formam uma instituição resiliente para atender as PAA. Estes atributos, na capacidade de colaboração, demonstram o quanto os indivíduos colaboram uns com os outros para a implementação das PAA, a capacidade da consciência da situação, lança luz sobre todas as capacidades operacionais da instituição, e a capacidade de adaptação, expressa a capacidade de uma instituição ou de suas partes para responder rapidamente à incerteza.

Para o terceiro estágio, Gibson e Tarrant (2010) consideram que a organização ao transitarem pelo primeiro estágio "despreparada - resposta reativa", no segundo estágio "competente proativamente - preparada" e no terceiro estágio da progressão da resiliência investem esforços na sua capacidade de resiliência e, eventualmente, neste terceiro estágio, a instituição alcança um estado adaptavelmente preparada.

No caso da UFMT, o estado adaptável não foi alcançado na sua plenitude, quando se analisa separadamente cada um dos atributos que incorporam a capacidade de adaptação. Por exemplo, na "capacidade da consciência da situação", constata-se pelas ações que a universidade desenvolve desde 2011, na aprovação das PAA, tem esta consciência no nível estratégico e intermediário, já no nível operacional, há indícios no material coletado que ela é inexistente. $\mathrm{Na}$ "capacidade de colaboração", compreende-se que a colaboração existe de maneira leve e fragmentada, isso porque muitos dos entrevistados declararam o desconhecimento sobre as PAA. A “capacidade de adaptação" de uma organização está ligada a sua capacidade de resposta e é definida como a habilidade de uma organização para desenvolver-se no sentido de acomodar as mudanças ou eventos adversos (McManus, 2008). Como tal, a capacidade de adaptação relaciona-se com a capacidade para expandir a área de variabilidade de uma resposta. Diante disto, compreende-se que a capacidade de adaptação está relacionada com a capacidade da consciência da situação e da capacidade da colaboração da universidade. Assim, diante dos fatores acima discutidos, entende-se que ainda existem muitas possibilidades para as capacidades de adaptação da universidade se aperfeiçoar. 


\section{Discussão}

O modelo de resiliência organizacional proposto por Gibson e Tarrant (2010), utilizado como base para a apresentação e discussão do caso da UFMT, auxiliou analisar com profundidade as capacidades de colaboração, adaptação, consciência da situação e a identificação das vulnerabilidades mais importantes de um ambiente, que, segundo os autores indicará uma medida para as capacidades de resiliência de uma organização. Contudo, os autores alertam que cada um desses atributos potencialmente funcionará de uma forma diferente e terá um nível de contribuição para a resiliência, a qual dependerá, essencialmente, das condições enfrentadas pela organização.

Exatamente isso foi constatado no estudo. A colaboração, a adaptação, a consciência da situação e a identificação das vulnerabilidades operam na construção das capacidades resilientes da IES estudada, mas em graus diferentes de contribuição. A capacidade de colaboração, por exemplo, que é uma característica muito importante da resiliência é um atributo pertencente ao nível de quem operacionaliza as políticas. Esta capacidade se apresentou de modo leve e fragmentado na IES. Sobre o assunto, os entrevistados relatam que “desconhecem como as PAA foram implementadas na universidade”. Quanto à comunicação, não é diferente, pois segundo eles "é distante, longa, burocrática a relação entre as unidades da universidade e o envolvimento da comunidade acadêmica com a implementação das PAA é quase inexistente". Os entrevistados revelam que não compreendem "as razões pelas quais levam os gestores da universidade a agirem desse modo em relação às unidades acadêmicas" e revelam que as políticas foram apresentadas pelos gestores na forma de um "pacote pronto e rápido", restando a eles a alternativa da "implementação das PAA nas respectivas unidades". O resultado não foi agradável, pois segundo eles "se vive uma realidade nos cursos, que os gestores desconhecem, causado pelo desconhecimento das PAA". "Não porque queremos", clamam os entrevistados, "mas porque não foi nos dado a oportunidade de participar, de opinar e de se envolver nesta nova história, que a UFMT começou a construir em 2003 e se consolidou em 2011 com a implementação das PAA".

Quanto à capacidade de adaptação, as PAA são perceptíveis em algumas ações que a universidade investiu esforços nesta direção. Como apresentado anteriormente, houve investimentos em estruturas, em sistemas de informações, na formulação de editais e a inclusão do tema PAA nos cursos de capacitação dos professores em estágio probatório. No entanto, na 
fala dos entrevistados, "as PAA não pertencem ao dia a dia do professor. Pouco se sabe sobre o andamento, o acompanhamento, a avaliação e os resultados de tais políticas e que gostariam que as PAA estivessem mais presentes no trabalho do docente da instituição". O mesmo foi encontrado na fala dos técnicos, que se dizem "esquecidos" e "desconsiderados" para contribuírem com a implementação das PAA. Eles argumentam que as políticas passam "longe" dos técnicos e que em "nenhum momento algum dos técnicos foi convidado para participar de sua implementação".

Na capacidade de consciência da situação, embora se constate que a universidade demonstrou esta capacidade ao longo de todos os estágios propostos no modelo, ela sozinha não conseguiu fazer com que a universidade desenvolva as capacidades resilientes. A capacidade de consciência da situação amplia a capacidade da organização sobre todo o seu ambiente, fornecendo a capacidade de reconhecer e agir de acordo com os riscos e oportunidades das diferentes condições (Seville, 2008). No caso da UFMT não foi o que aconteceu. Os fatos indicam que a universidade poderia ter construído uma história diferente sobre as PAA, mas por razões desconhecidas não o fez.

No que tange a capacidade de identificação das vulnerabilidades, a UFMT inicialmente demonstra que pouco sabe sobre suas vulnerabilidades, tanto que propõe a constituição do comitê em 2003, data em que aprovou no mérito as políticas de sobrevagas, para que estudasse, consultasse e apresentasse sugestão para a implementação das PAA junto às unidades acadêmicas. Contudo, o que se sabe é que isso não aconteceu. Então fica a dúvida se a universidade desconhecia as suas vulnerabilidades ou esta era uma estratégia utilizada pelos membros do CONSEPE para aliviar o peso da responsabilidade que estava naquele momento sobre a aprovação das PAA.

\section{Considerações Finais}

Este artigo teve como objetivo realizar uma análise das capacidades resilientes de uma IES diante da implementação de PAA. Para tanto foi considerado como base inicial o modelo proposto por Gibson e Tarrant (2010), que propõe mensurar uma variedade de atributos, aqui representado pelas capacidades de colaboração, adaptação, consciência da situação e a identificação das vulnerabilidades mais importantes em um ambiente, se traduzirá em uma 
medida das capacidades de resiliência. No caso da IES estudada, percebeu-se que a falta de envolvimento de pessoas atuantes no processo das PAA acabou por restringir o efeito da capacidade de colaboração na IES, interferindo de forma negativa na capacidade de resiliência. Outra capacidade que foi observada que necessita de reforço nesta IES é a identificação das vulnerabilidades da adoção e gestão das PAA, o que também fragiliza a ação da capacidade de resiliência organizacional.

Como sugestões dos próprios entrevistados se faz necessário (1) a universidade assumir as PAA; (2) implementar o Comitê de professores; (3) elaborar o planejamento estratégico para as PAA; (4) desenvolver instrumentos de reconhecimento para os membros constituintes do conselho das PAA; (5) aperfeiçoar os canais de comunicação; (6) descentralizar a tomada de decisão em relação às PAA; (7) melhorar os sistemas e procedimentos nas unidades acadêmicas em relação às PAA; (8) melhorar os investimentos em acessibilidade em todos os campus da universidade, e (9) reinventar seus instrumentos de conexões, entre pessoas, departamentos, unidades e campus da instituição.

Quanto às limitações do estudo centra-se em realizar o estudo empírico apenas em uma instituição, o qual se compreende como um fator limitante para estender os resultados do estudo para outras instituições. Diante destes resultados, novos estudos devem ser realizados para que se possa avançar na direção de um melhor entendimento do que as capacidades de resiliência representam para uma organização, principalmente quando esta instituição é pública e atua em um ambiente dinâmico, complexo e multifacetado. A mesma recomendação se faz para os estudos sobre as PAA, pois se faz necessário estudos que discutam essencialmente, o acompanhamento, monitoramento e avaliação da eficácia dessas políticas na vida dos estudantes nas universidades brasileiras.

\section{Referências}

Aprile, M. R., \& Barone, R. E. M. (2009). Educação superior: políticas públicas para inclusão social. Revista Ambiente Educação, 2(1), 39-55.

Bardin, L. (2011). Análise de conteúdo. São Paulo: Edições 70.

Benedito, V. L. (2006). Ações afirmativas à brasileira: em busca do consenso. Caderno CRH, 15(36). 
Boin, A., \& Van Eeten, M. J. (2013). The resilient organization. Public Management Review, $15(3), 429-445$.

Burnard, K., \& Bhamra, R. (2011). Organisational resilience: development of a conceptual framework for organisational responses. International Journal of Production Research, 49(18), 5581-5599.

Capano, G., \& Woo, J. J. (2017). Resilience and robustness in policy design: A critical appraisal. Policy Sciences, 1-28.

Cho, S., Mathiassen, L., \& Robey, D. (2007). Dialectics of resilience: a multi-level analysis of a telehealth innovation. Journal of Information Technology, 22(1), 24-35.

Cruz Neto, O., \& Moreira, M. R. (1999). A concretização de políticas públicas em direção à prevenção da violência estrutural. Ciência \& Saúde Coletiva, 4 (1), 33-52.

Daflon, V. T., Feres Júnior, J., \& Campos, L. A. (2013). Ações afirmativas raciais no ensino superior público brasileiro: um panorama analítico. Cadernos de Pesquisa, 43(148), 302-327.

Da Silva, S. P. M. (2005). Discriminação positiva: ações afirmativas na realidade brasileira. Brasília Jurídica.

Dos Santos, A. P. (2012). Itinerário das ações afirmativas no ensino superior público brasileiro: dos ecos de Durban à Lei das Cotas.

Feres Júnior, J., Daflon, V., \& Campos, L. A. (2011). A ação afirmativa no ensino superior brasileiro - (GEMAA). Rio de Janeiro: IESP-UERJ.

Feres Júnior, J., \& Daflon, V. (2014). Políticas da igualdade racial no ensino superior. Cadernos do Desenvolvimento Fluminense, (5), 31-44.

Feres Júnior, J., Daflon, V., Ramos, P., \& Miguel, L. (2013). O impacto da Lei n ${ }^{\circ} 12.711$ sobre as universidades federais. Levantamento das políticas de ação afirmativas (GEMAA)(Rio de Janeiro: IESP-UERJ) setembro, 1-34.

Erol, O., Sauser, B. J., \& Mansouri, M. (2010). A framework for investigation into extended enterprise resilience. Enterprise Information Systems, 4(2), 111-136.

Gibson, C. A., \& Tarrant, M. (2010). A conceptual models approach to organisational resilience. Australian Journal of Emergency Management, 25(2), 6. 
Gittell, J. H., Cameron, K., Lim, S., \& Rivas, V. (2006). Relationships, layoffs, and organizational resilience: Airline industry responses to September 11. The Journal of Applied Behavioral Science, 42(3), 300-329.

Godoy, A. S. (1995). Introdução à pesquisa qualitativa e suas possibilidades. Revista de Administração de Empresas, 35(2), 57-63.

Godwin, I., \& Amah, E. (2013). Knowledge management and organizational resilience in Nigerian manufacturing organizations. Developing Country Studies, 3(9), 104-120.

Gomes, J. B. B., \& Silva, F. D. L. L. D. (2001). As ações afirmativas e os processos de promoção da igualdade efetiva. Cadernos do CEJ, 24, 86-123.

Goldemberg, J., \& Durham, E. R. (2007). Cotas nas universidades públicas. Divisões perigosas: políticas raciais no Brasil contemporâneo. Rio de Janeiro: Editora Civilização Brasileira, pp. 167-172.

GEMAA - Grupo de Estudos Multidisciplinares da Ação Afirmativa. (2011). "Ações afirmativas".

Haas, C. M., \& Linhares, M. (2013). Políticas públicas de ações afirmativas para ingresso na educação superior se justificam no Brasil? Revista Brasileira de Estudos Pedagógicos, 93(235), 836-863.

Hamel, G., \& Valikangas, L. (2003). The quest for resilience. Harvard Business review, 81(9), $52-65$.

Heringer, R. (2014). Um balanço de 10 anos de políticas de ação afirmativa no Brasil. Revista TOMO.

Horne, J. F., \& Orr, J. E. (1997). Assessing behaviors that create resilient organizations. Employment Relations Today, 24(4), 29-39.

Leite, J. L. (2011). Política de cotas no Brasil: política social?. Revista Katálysis, 14(1).

Lengnick-Hall, C. A., Beck, T. E., \& Lengnick-Hall, M. L. (2011). Developing a capacity for organizational resilience through strategic human resource management. Human Resource Management Review, 21(3), 243-255.

McCann, J., Selsky, J., \& Lee, J. (2009). Building agility, resilience and performance in turbulent environments. People and Strategy, 32(3), 44-51.

McManus, S. T. (2008). Organisational resilience in New Zealand. Tese de Doutorado. University of Canterbury. 
Medeiros, C. A. (2005). Ação Afirmativa no Brasil: um debate em curso. Ações Afirmativas e Combate ao Racismo nas Américas, 121.

Moehlecke, S. (2002). Ação afirmativa: história e debates no Brasil. Cadernos de Pesquisa, 117(11), 197-217.

Moura, D. M. D. (2014). Políticas públicas educacionais PROUNI e FIES: democratização do acesso ao ensino superior. Seminário Internacional de Demandas Sociais e Políticas Públicas na Sociedade Contemporânea, (11).

Munanga, K. (2001). Políticas de ação afirmativa em benefício da população negra no Brasil: um ponto de vista em defesa de cotas. Sociedade e cultura, 4(2).

Passos, J. C. (2015). Relações raciais, cultura acadêmica e tensionamentos após ações afirmativas. Educação em Revista, 31(2), 155-182.

Pellissier, R. (2010). The implementation of resilience engineering to enhance organizational innovation in a complex environment. International Journal of Business and Management, 6(1), 145.

Pereira, T. I., \& da Silva, L. F. S. C. (2010). As políticas públicas do ensino superior no governo Lula: expansão ou democratização?. Revista Debates, 4 (2), 10.

Richardson, R. J., \& Peres, J. A. (1989). Pesquisa social: métodos e técnicas. São Paulo: Atlas. Salgado, C. M. (2012). La Resiliencia y su empleo en las organizaciones. Gestión y Estratégia, 41, pp. 29-39.

Segato, R. L. (2006). Cotas: por que reagimos?. Revista USP, (68), 76-87.

Seville, E. (2008). Resilience: Great Concept But What Does It Mean?. Paper Presented at the US Council on Competitiveness Workshop, Risk and Resilience. Wilmington, USA.

Sheffi, Y. (2007). Building a resilient organization. Bridge-Washington-National Academy of Engineering, 37(1), 30.

Souza, E. A. D., \& Pereira, R. D. R. (2016). Políticas de ações afirmativas e os desafios da universidade no século XXI. Simpósio Nacional de Educação (9.: 2016: Frederico Westphalen, RS). Anais. Frederico Westphalen.

Starr, R., Newfrock, J., \& Delurey, M. (2003). Enterprise resilience: managing risk in the networked economy. Strategy and Business, 30, 70-79.

Sutcliffe, K. M., \& Vogus, T. J. (2003). Organizing for resilience. Positive Organizational Scholarship, 94-110. 
Toubia, A. A. T., \& Lima, P. G. (2015). Ações afirmativas na educação: os avanços na realidade brasileira na perspectiva da universidade para todos. Laplage em Revista, 1(3), 118-129.

Universidade Federal de Mato Grosso. (2010). Relatório de Avaliação Institucional 2014. Cuiabá-MT, Reitoria /UFMT.

Universidade Federal de Mato Grosso. (2009). Resolução CONSEPE $N^{o} 110$, DE 10 de novembro de 2003/UFMT.

Whitehorn, G. (2010). Building Organisational Resilience, in the Public Sector. In Comcover Insurance and Risk Management Conference (Vol. 21).

Vickers, M. H., \& Kouzmin, A. (2001). 'Resilience'in organizational actors and rearticulating 'voice': towards a humanistic critique of New Public Management. Public Management Review, 3(1), 95-119.

Yin, R. K. (2010). Estudo de Caso-: Planejamento e Métodos. (4a ed.). Porto Alegre: Bookman editora.

Yunes, M. A. M., Szymanski, H., \& Tavares, J. (2001). Resiliência: noção, conceitos afins e considerações críticas. Resiliência e Educação, 2, 13-43.

Zolkoski, S. M., \& Bullock, L. M. (2012). Resilience in children and youth: A review. Children and Youth Services Review, 34(12), 2295-2303. 